\title{
Antibacterial and Antibiofilm Activity and Mode of Action of Magainin 2 against Drug-Resistant Acinetobacter baumannii
}

\author{
Min Kyung Kim ${ }^{1}$, Na Hee Kang ${ }^{1}$, Su Jin Ko ${ }^{1}$, Jonggwan Park ${ }^{2}$, Eunji Park ${ }^{1}$, Dong Won Shin ${ }^{3}$, \\ Seo Hyun Kim ${ }^{3}$, Seung A. Lee ${ }^{3}$, Ji In Lee ${ }^{3}$, Seung Hyun Lee ${ }^{3}$, Eun Gi Ha ${ }^{3}$, Seung Hun Jeon ${ }^{3}$ \\ and Yoonkyung Park ${ }^{1,4, *}$ \\ 1 Department of Biomedical Science, Chosun University, Gwangju 61452, Korea; \\ charm5964@naver.com (M.K.K.); govlgovl_2414@hanmail.net (N.H.K.); \\ ksj920708@hanmail.net (S.J.K.); fhhhhgfh@naver.com (E.P.) \\ 2 Department of Bioinformatics, Kongju National University, Kongju 38065, Korea; for_quality@naver.com \\ 3 Jangseong High School, Jeollanamdo 57216, Korea; dkatlf6017@naver.com (D.W.S.); \\ twinpearl@naver.com (S.H.K.); iceone256325@naver.com (S.A.L.); jiin1839@gmail.com (J.I.L.); \\ dltmdzus4001@naver.com (S.H.L.); dwar77@naver.com (E.G.H.); bioman255@naver.com (S.H.J.) \\ 4 Research Center for Proteineous Materials, Chosun University, Gwangju 61452, Korea \\ * Correspondence: y_k_park@chosun.ac.kr; Tel.: +82-62-230-6854; Fax: +82-62-225-6758
}

Received: 6 September 2018; Accepted: 28 September 2018; Published: 5 October 2018

\begin{abstract}
Antimicrobial peptides (AMPs) are promising therapeutic agents for treating antibioticresistant bacterial infections. Previous studies showed that magainin 2 (isolated from African clawed fogs Xenopus laevis) has antimicrobial activity against gram-positive and gram-negative bacteria. The present study was conducted to investigate the antibacterial activity of magainin 2 against Acinetobacter baumannii. Magainin 2 showed excellent antibacterial activity against $A$. baumannii strains and high stability at physiological salt concentrations. This peptide was not cytotoxic towards HaCaT cells and showed no hemolytic activity. Biofilm inhibition and elimination were significantly induced in all A. baumannii strains exposed to magainin 2. We confirmed the mechanism of magainin 2 on the bacterial outer and inner membranes. Collectively, these results suggest that magainin 2 is an effective antimicrobial and antibiofilm agent against $A$. baumannii strains.
\end{abstract}

Keywords: Acinetobacter baumannii; multidrug-resistant; antimicrobial peptide; antibiofilm activity; physiological salt

\section{Introduction}

The use of antibiotics for treating infections has resulted in the emergence of resistant strains [1]. New antibiotic-resistant strains are becoming a problem worldwide because conventional antibiotics cannot be administered. A recent report using data from the Infectious Diseases Society of America and hospital-based surveillance research refers to the pathogens as "ESKAPE" [2,3]. The ESKAPE pathogens include Enterococcus faecium, Staphylococcus aureus, Klebsiella pneumoniae, Acinetobacter, Pseudomonas aeruginosa, and Enterobacter species [4]. The ability of these bacteria groups to withstand antibiotic treatment is a major cause of hospital infections worldwide [5]. Notably, Acinetobacter baumannii has been reported as one of the most serious ESKAPE organisms resistant to antibiotics [6].

Acinetobacter baumannii, a gram-negative bacterium, is an opportunistic bacterial pathogen and has a high morbidity and mortality, especially in intensive care units with high pathogen infections. Infectious diseases include urinary tract infection [7], meningitis [8], skin infection [9], bacteremia [10], and pneumonia [11]. Many strains causing infection show resistance to antibiotics such as 
aminoglycosides, fluoroquinolones, colistin, $\beta$-lactams, and tetracyclines $[12,13]$. Also, A. baumannii is prone to biofilm formation and their ability to increase resistance to antibiotics.

Biofilm is a microbial aggregate formed by cells and cells that attach to each other and become embedded in a matrix of self-generated extracellular polymeric substances [14]. Biofilms can form on various abiotic surfaces including glass, polystyrene, and surgical instruments. They can also attach to tissues that are easily exposed to bacterial infections and cause problems [15]. Therefore, new drugs are needed to effectively treat antibiotic-resistant bacteria and biofilm-related infections. Antimicrobial peptides (AMPs) are excellent candidates for developing therapeutic agents.

AMPs are an essential component of innate immunity in host organisms, including animals, insects, plants, and humans [16]. Human host defense antimicrobial peptides are a major component of innate immunity and play an important role in preventing microbial infection and these peptides expressed in the skin, eyes, ears, and various tissues [17]. Among them, Defensins, LL-37 and Histatins are important to prevent oral cavity [18-20]. These molecules are amphipathic peptides typically composed of 12-50 amino acids and show antimicrobial activity against a broad spectrum of microorganisms including gram-positive and gram-negative bacteria, fungi, viruses, and cancer cells. These peptides contain arginine and lysine, which are positively charged and important in their mechanism of action [21]. In general, the bacterial membrane contains a higher content of negatively charged phospholipids compared to mammalian cells, enabling the positively charged peptide to bind more strongly with bacterial cells through electrostatic interactions. This destabilizes or disrupts the bacterial membrane and intracellular processes, leading to microorganism death.

Frog skin is the most abundant source of antimicrobial peptides [22] and secretes major peptides such as esculentin [23], temporin [24] and magainin [25] to protect against microbial invasion. AMPs and its analogue peptides detected in the skin of many frogs exhibit strong antimicrobial activity against antibiotic-resistant bacteria. We previously investigated magainin 2 (GIGKFLHSAKKFGKAFVGEIMNS), an antimicrobial peptide consisting of 23 amino acids isolated from the skin of the African clawed frog Xenopus laevis [25]. This peptide has been reported to exhibit broad antibacterial activity against gram-positive and gram-negative bacteria and anti-cancer activity against certain tumor cell lines [26,27].

In this study, we examined the antimicrobial activity of magainin 2 against $A$. baumannii strains and its toxicity towards mammalian cells. We also confirmed that the antibacterial activity of the peptide was maintained even under high-salt conditions. Next, we investigated the activity in a biofilm model, which is closely related to bacterial resistance. The mechanism of action of the peptide was confirmed by membrane-related experiments using $N$-phenyl-1-naphthylamine (NPN) and 3,3'-dipropylthiadicarbocyanine iodide $\left(\mathrm{DiSC}_{3}-5\right)$. Our results suggest that magainin 2 can be used as an effective treatment for $A$. baumannii infections.

\section{Results}

\subsection{Peptide Synthesis}

The magainin 2 sequence, observed molecular weight, hydrophobicity, hydrophobic moment, and net charge are summarized in Table 1. Magainin 2 is an antimicrobial peptide consisting of 23 amino acids with hydrophobic content, hydrophobic moment, and net charge of $0.373,0.475$, and 3 , respectively. The wheel diagram and three-dimensional structure analysis predicted that the peptide contains hydrophobic residues (yellow circles) and forms an $\alpha$-helix structure (Figure 1).

Table 1. Amino acid sequence and properties of magainin 2.

\begin{tabular}{cccccc}
\hline Name & Sequence & Molecular Mass (Da) & $\mathbf{H}$ & $\boldsymbol{\mu H}$ & Net Charge \\
\hline Magainin 2 & GIGKFLHSAKKFGKAFVGEIMNS-NH 2 & 2465.9 & 0.373 & 0.475 & +3 \\
\hline H: Hydrophobicity; $\mu \mathrm{H} \cdot$ Hydrophobic moment \\
\hline
\end{tabular}

H: Hydrophobicity; $\mu \mathrm{H}$ : Hydrophobic moment. 
A

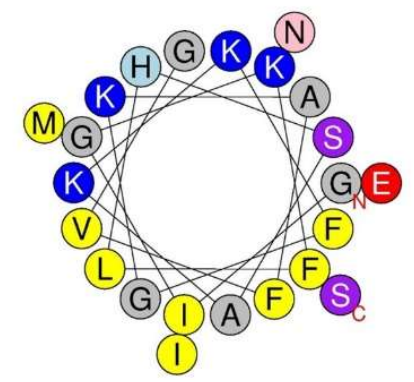

B

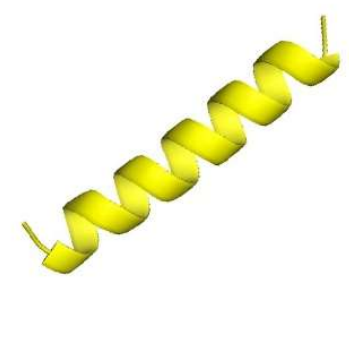

Figure 1. Structure analysis of magainin 2. (A) Helical wheel diagram of the peptide. The projection was obtained from http:/ /heliquest.ipmc.cnrs.fr/cgibn/ComputParam.py. Positively charged residues are represented in blue, while hydrophobic residues are shown as yellow circles. The N-terminal and C-terminal parts are represented in red letters " $\mathrm{N}$ " and " $\mathrm{C}$ ". (B) Three-dimensional structure of magainin 2.

\subsection{Circular Dichroism Measurements}

Based on the predicted results shown in Figure 1B; we measured the secondary structure of magainin 2 by circular dichroism (CD) spectroscopy. Structure analysis of magainin 2 was performed in various concentrations of trifluoroethanol (TFE) and sodium dodecyl sulfate (SDS) solutions (Figure 2). In $10 \mathrm{mM}$ sodium phosphate buffer; the CD spectra of the peptide displayed a random coil. However; the peptide adopted a typical $\alpha$-helical conformation with increasing TFE and SDS concentrations. The calculated $\alpha$-helical contents of the peptide are shown in Table 2. As the TFE and SDS concentration increased; the $\alpha$-helical contents increased from $6.4 \%$ to $50.8 \%$ and from $21.8 \%$ to $33.3 \%$; respectively. These results demonstrate that magainin 2 forms a strong $\alpha$-helix structure.

A

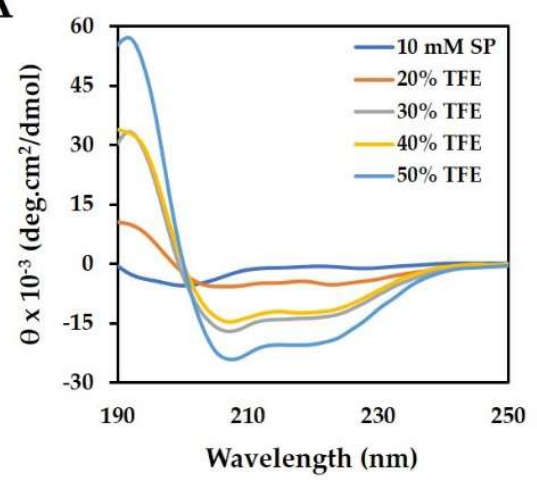

B

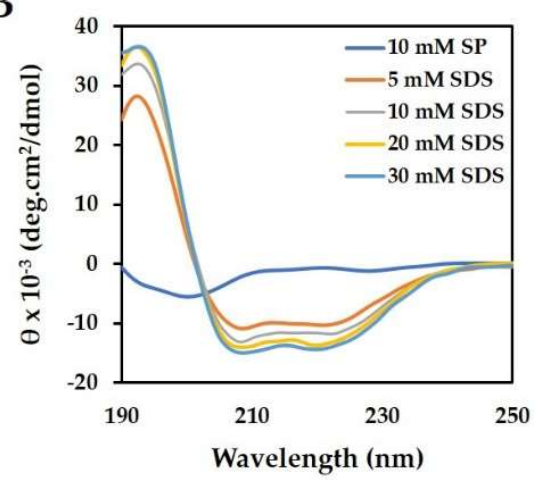

Figure 2. Circular dichroism (CD) spectra of magainin 2. (A) The peptide was measured in TFE, which mimics the hydrophobic environment of the microbial membrane and (B) SDS, which mimics the negatively charged prokaryotic membrane environment.

Table 2. Mean residual ellipticity at $222 \mathrm{~nm}\left([\theta]_{222}\right)$ and percent $\alpha$-helical contents of magainin 2 in various solutions.

\begin{tabular}{cccccccccc}
\hline & Buffer & \multicolumn{4}{c}{ TFE } & \multicolumn{4}{c}{ SDS } \\
\cline { 2 - 9 } & $\mathbf{1 0 ~} \mathbf{~ m M ~ S P ~}$ & $\mathbf{2 0} \%$ & $\mathbf{3 0} \%$ & $\mathbf{4 0} \%$ & $\mathbf{5 0} \%$ & $\mathbf{5} \mathbf{~ M M}$ & $\mathbf{1 0} \mathbf{~ m M}$ & $\mathbf{2 0} \mathbf{~ m M}$ & $\mathbf{3 0} \mathbf{~ m M}$ \\
\hline$[\theta]_{222}$ & -700.8 & -5128.3 & $-13,207.4$ & $-11,989$ & $-19,749.5$ & $-10,184.8$ & $-11,782$ & $-13,227.2$ & $-13,974.2$ \\
$\% \alpha$-helix & RC & 6.4 & 30.9 & 27.2 & 50.8 & 21.8 & 26.6 & 31.0 & 33.3 \\
\hline \multicolumn{1}{c}{10 mM SP: 10 mM Sodium Phosphate buffer, $\mathrm{pH} 7.2}$.
\end{tabular}




\subsection{Antimicrobial Assay}

The antimicrobial activity of the peptides against A. baumannii strains are summarized in Table 3. We compared the antibacterial effect of magainin 2 with those of melittin, buforin 2, ciprofloxacin, and gentamicin. Magainin 2 showed strong antibacterial activity with minimum inhibitory concentrations (MICs) of 4 and $2 \mu \mathrm{M}$ against the standard strain (Korea Collection for Type Cultures (KCTC) 2508) and drug-resistant strains, respectively. This is similar to the MIC of melittin, which is known to have strong antibacterial activity. The activity of buforin 2 was 8-fold lower, ranging from 8 to $16 \mu \mathrm{M}$. Antibiotics showed activity against drug-resistant strains at $128 \mu \mathrm{M}$. Particularly, gentamicin showed low antibacterial activity with an MIC of $256 \mu \mathrm{M}$.

Table 3. Minimum inhibitory concentration (MIC) of peptides and conventional agents against Acinetobacter baumannii strains.

\begin{tabular}{cccccc}
\hline \multirow{2}{*}{ Microorganisms } & \multicolumn{5}{c}{ Minimum Inhibitory Concentration $(\mu \mathrm{M})$} \\
\cline { 2 - 6 } & Magainin 2 & Buforin 2 & Melittin & Ciprofloxacin Gentamicin \\
\hline A. baumannii KCTC 2508 & 4 & 8 & 2 & 2 & 4 \\
A. baumannii 244752 & 2 & 8 & 2 & 256 & $>256$ \\
A. baumannii 409081 & 2 & 8 & 1 & $>256$ & $>256$ \\
A. baumannii 719705 & 2 & 8 & 2 & 128 & $>256$ \\
A. baumannii 892199 & 2 & 16 & 2 & 256 & $>256$ \\
A. baumannii 907233 & 2 & 16 & 2 & 128 & $>256$ \\
\hline
\end{tabular}

\subsection{Cytotoxicity Assay}

Hemolysis and cell viability assays were conducted to measure the toxicity of the peptides in mammalian cells. As shown in Figure 3A, melittin, a positive control peptide, induced more than 50\% hemolysis at concentrations of 1-2 $\mu \mathrm{M}$. In contrast, magainin 2-treated cells showed no hemolysis at $64 \mu \mathrm{M}$. We confirmed the cytotoxicity of magainin 2 in HaCaT cells. The curve in Figure 3B shows that high concentrations of magainin 2 exhibited low cytotoxicity of $0 \%$, while melittin exhibited $100 \%$ toxicity at $2 \mu \mathrm{M}$. These results confirm that magainin 2 is not toxic to cells.
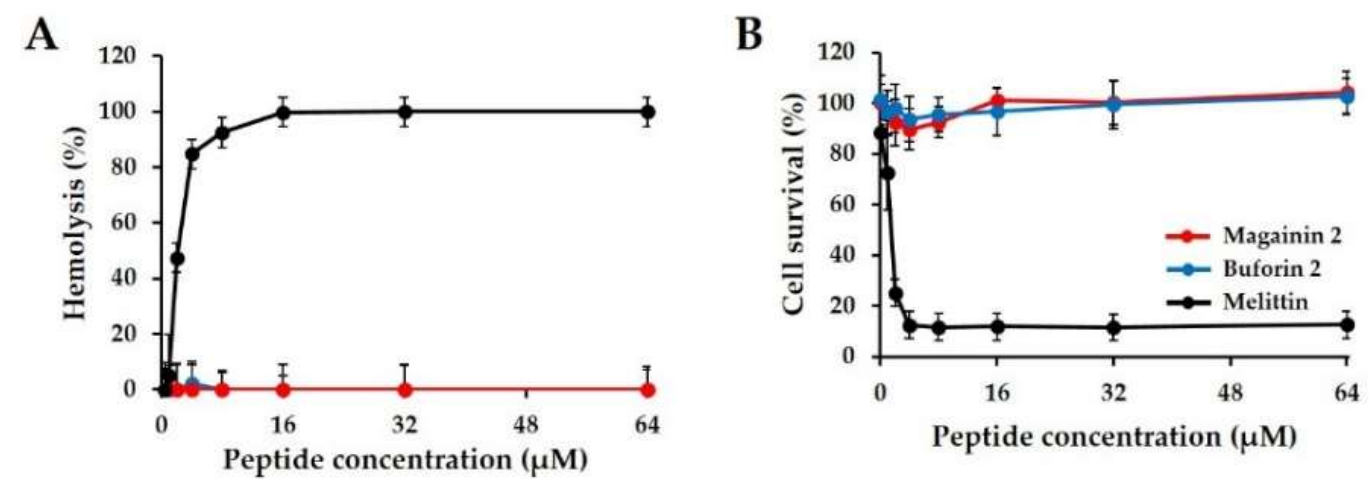

Figure 3. Cytotoxicity and hemolytic activity of magainin 2. (A) Hemolytic activity of peptides against mouse red blood cells (RBCs). (B) Cytotoxicity of peptides against HaCaT cells.

\subsection{Biofilm Inhibition Assay}

To investigate whether magainin 2 can inhibit biofilm formation, the degree of biofilm formation by A. baumannii strains was confirmed in Mueller-Hinton broth (MHB) supplemented with glucose. As shown in Figure 4A, all strains formed biofilms and the A. baumannii 907233 strain had a biofilm mass of 3 at OD $595 \mathrm{~nm}$. Compared to A. baumannii KCTC 2508 in the crystal violet staining assay, A. baumannii 907233 showed a $57.6 \%$ higher biofilm mass after $24 \mathrm{~h}$ of incubation (Figure $4 \mathrm{~A}$ ). The ability of magainin 2 and antibiotics (ciprofloxacin, gentamicin) to prevent biofilm formation was compared. 
Magainin 2 and antibiotics inhibited the biofilm formation of A. baumannii KCTC 2508 at concentrations of 2-8 $\mu \mathrm{M}$, whereas buforin 2 showed inhibition at $64 \mu \mathrm{M}$. In resistant strains, magainin 2 inhibited biofilm formation at a low concentration of $4 \mu \mathrm{M}$, while the antibiotics did not exhibit biofilm formation inhibition activity until $32 \mu \mathrm{M}$ (Figure 4B). The biofilm biomass was determined using the green dye SYTO9 and detected with the EVOS AUTO2 fluorescence microscope. Acinetobacter baumannii 907233 formed biofilm showing strong green fluorescence (Figure 5). Following treatment of the biofilm with magainin 2, SYTO9 fluorescence decreased in a concentration-dependent manner, while this was not observed following treatment with the other antibiotics. This data shows that magainin 2 has strong antibiofilm activity against drug-resistant $A$. baumannii.

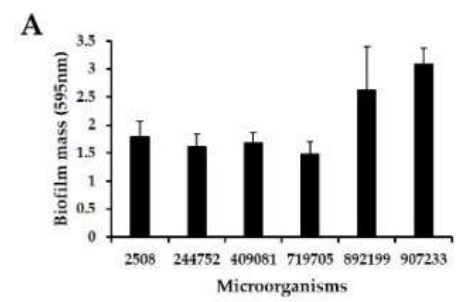

B
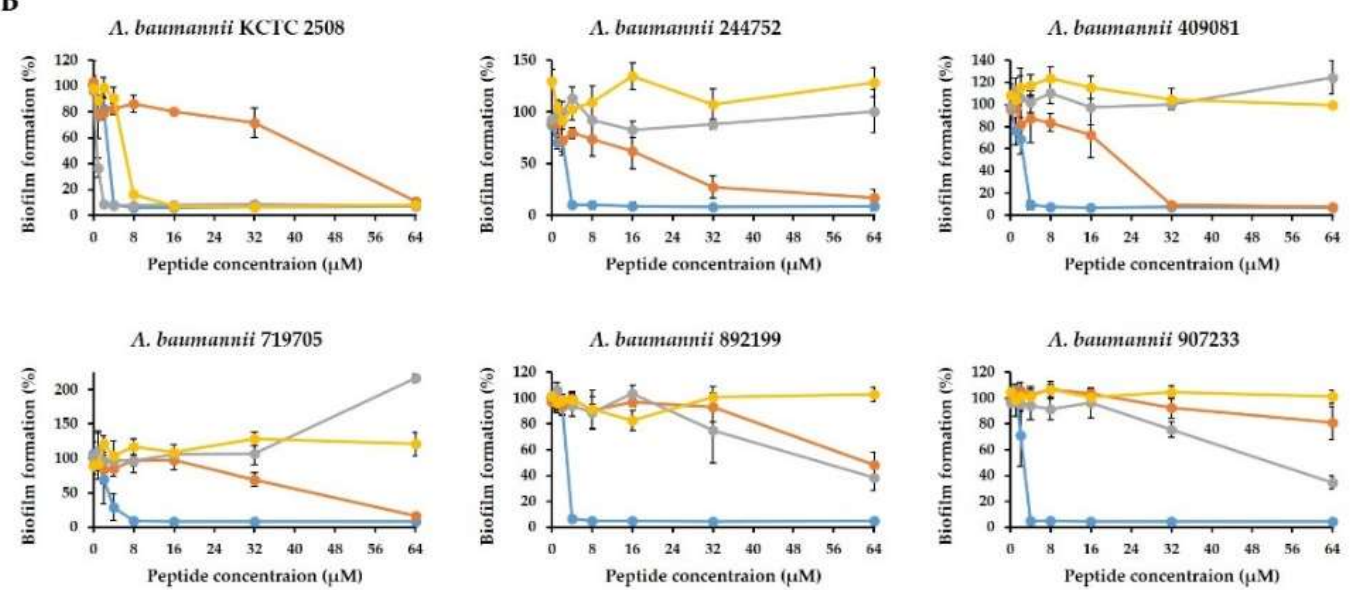

- Magainin $2-$ Buforin $2 \rightarrow$ Ciprofloxacin - Gentamicin

Figure 4. Effect of Acinetobacter baumannii biofilm formation by magainin 2. (A) Quantitative measurements of biofilm formation using crystal violet staining. (B) Inhibitory effect of peptides on biofilm formation. Antibiotics (ciprofloxacin and gentamicin) and buforin 2 were used as controls.

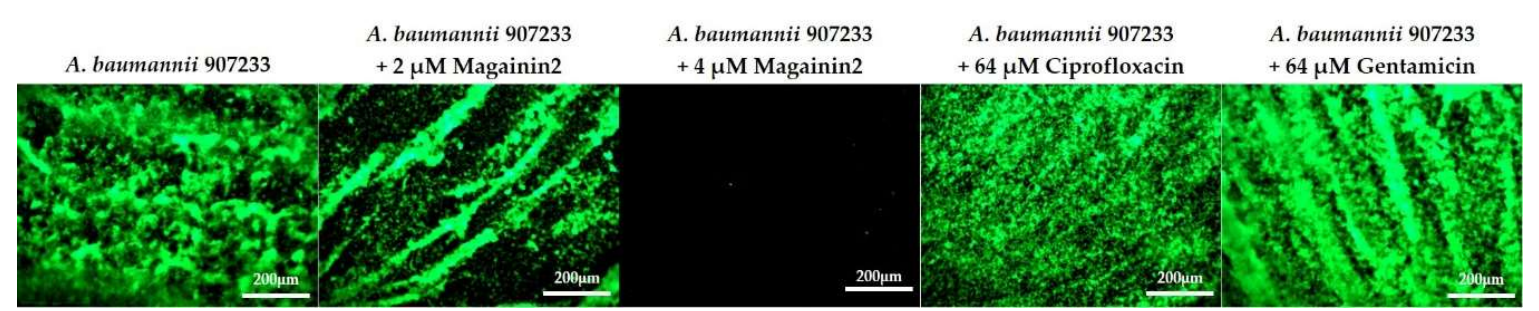

Figure 5. EVOS2 images of Acinetobacter baumannii biofilm stained with SYTO9 dye (green fluorescence).

\subsection{Biofilm Reduction Assay}

The biofilm reduction activity of magainin 2 was confirmed against A. baumannii 907233, which easily forms biofilm. Figure 6 shows the effect of the peptide and antibiotics on biofilm formed for $24 \mathrm{~h}$. In the crystal violet staining assay, A. baumannii 907233 showed strong staining after incubation for $24 \mathrm{~h}$ (Figure 6B). Antibacterial treatment with magainin 2 and ciprofloxacin exhibited similar abilities to eradicate biofilm formation. The biofilm inhibition rates of magainin 2 were $33.3 \%$, $53.4 \%$, and $66.2 \%$ at 128,192 , and $256 \mu \mathrm{M}$, respectively. In contrast, gentamicin showed no biofilm 
inhibition effects at $256 \mu \mathrm{M}$ (Figure 6A). Next, the biofilm was observed using SYTO9 (green dye). After $24 \mathrm{~h}$, the biofilm stained with SYTO9 showed strong green fluorescence. The fluorescence was low in the presence of $256 \mu \mathrm{M}$ magainin 2, indicating that it effectively disrupted the biofilm. Gentamicin showed no decrease in biofilm (Figure 6C). These results suggest that magainin 2 not only inhibits but also effectively eliminates biofilm.

A

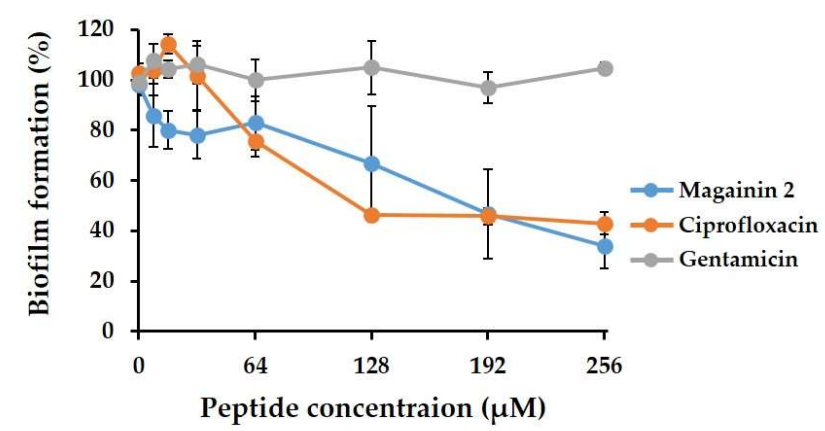

B

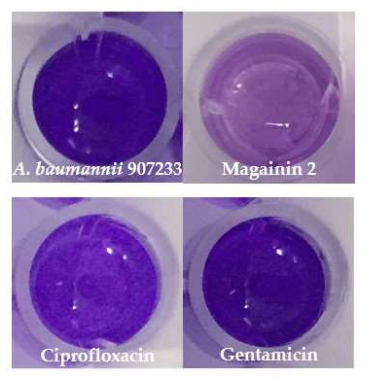

C

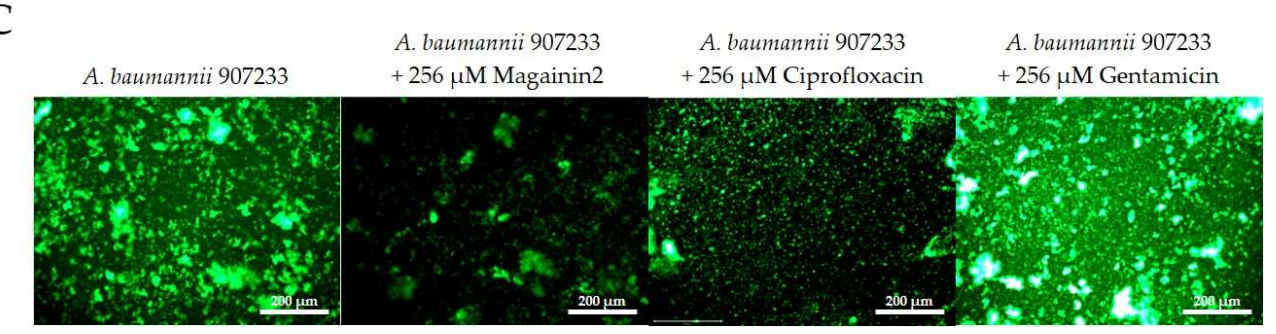

Figure 6. Biofilm reduction assay. (A) Degree of biofilm removal by magainin 2, ciprofloxacin, and gentamicin using crystal violet staining. (B) Image of removed biofilm after treatment with $256 \mu \mathrm{M}$ of peptide and antibiotics. (C) SYTO9-stained biofilm image.

\subsection{Salt Sensitivity Assay}

To investigate the effects of salts on antimicrobial activity, antimicrobial activity was measured at a physiological salt concentration (Table 4). As shown in Table 3, magainin 2 exhibited similar stability in the presence of physiological salts compared to buforin 2. The MIC values of A. baumannii KCTC 2508 and A. baumannii 907233 strain were 4 and $2 \mu \mathrm{M}$, respectively. In the presence of $\mathrm{NaCl}$ and $\mathrm{FeCl}_{3}$, magainin 2 activity was nearly maintained in both strains. In contrast, magainin 2 activity was slightly reduced to $8 \mu \mathrm{M}$ in the presence of $\mathrm{MgCl}_{2}$.

Table 4. MIC values of peptides in the presence of physiological salts.

\begin{tabular}{cccccc}
\hline \multirow{2}{*}{ Salt } & Concentration & \multicolumn{2}{c}{ A. baumannii KCTC 2508 } & \multicolumn{2}{c}{ A. baumannii $\mathbf{9 0 7 2 3 3}$} \\
\cline { 3 - 6 } & & Magainin 2 & Buforin 2 & Magainin 2 & Buforin 2 \\
\hline \multirow{3}{*}{$\mathrm{NaCl}$} & $50 \mathrm{mM}$ & 4 & 16 & 2 & 32 \\
& $100 \mathrm{mM}$ & 4 & 32 & 4 & $>32$ \\
& $150 \mathrm{mM}$ & 4 & $>32$ & 4 & $>32$ \\
\hline \multirow{3}{*}{$\mathrm{MgCl}_{2}$} & $0.5 \mathrm{mM}$ & 4 & 16 & 4 & $>32$ \\
& $1 \mathrm{mM}$ & 8 & 32 & 8 & $>32$ \\
& $2 \mathrm{mM}$ & 8 & $>32$ & 8 & $>32$ \\
\hline \multirow{2}{*}{$\mathrm{FeCl}_{3}$} & $2 \mu \mathrm{M}$ & 4 & 4 & 2 & 16 \\
& $4 \mu \mathrm{M}$ & 4 & 4 & 2 & 16 \\
& $8 \mu \mathrm{M}$ & 4 & 4 & 2 & 16 \\
\hline
\end{tabular}




\subsection{Mechanism of Action Of Magainin 2}

To investigate the mechanism of magainin 2 activity towards drug-resistant bacteria, A. baumannii 907233 was used, while A. baumannii KCTC 2508 as a control strain. First, the outer membrane permeability of $A$. baumannii 907233 following treatment with magainin 2 was examined using NPN dye (hydrophobic fluorescent dye, exhibits fluorescence intensity in a hydrophobic environment). The bacterial outer membrane was disrupted, and the hydrophobic part of the membrane was exposed, after which NPN reacted to show fluorescence. As shown in Figure 7A,B, the intensity increased in a concentration-dependent manner, indicating that magainin 2 acts on the outer membrane. For A. baumannii KCTC 2508, the fluorescence intensity rapidly increased to 268, 246, and 209 within $2 \mathrm{~min}$ at $4 \times, 2 \times$, and $1 \times \mathrm{MIC}$, respectively. In contrast, fluorescence increased to approximately 80 in A. baumannii 907233 .

A

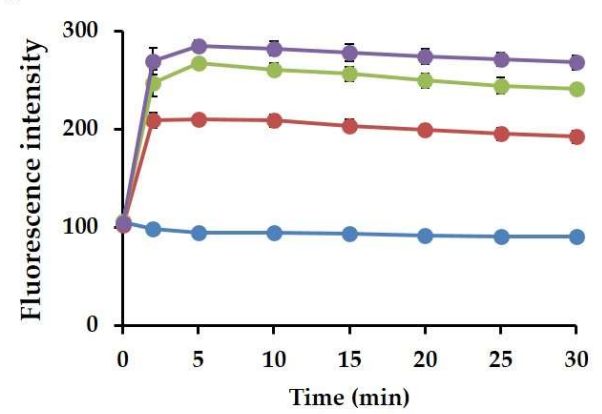

C

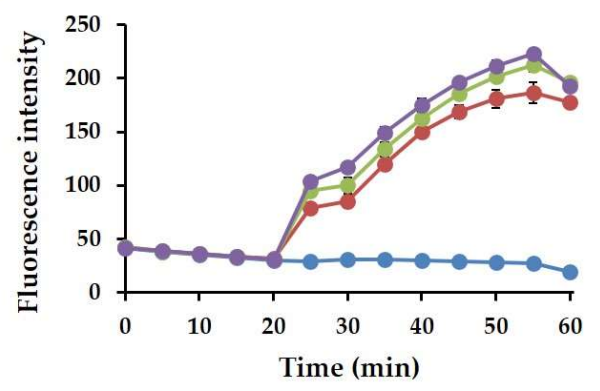

B

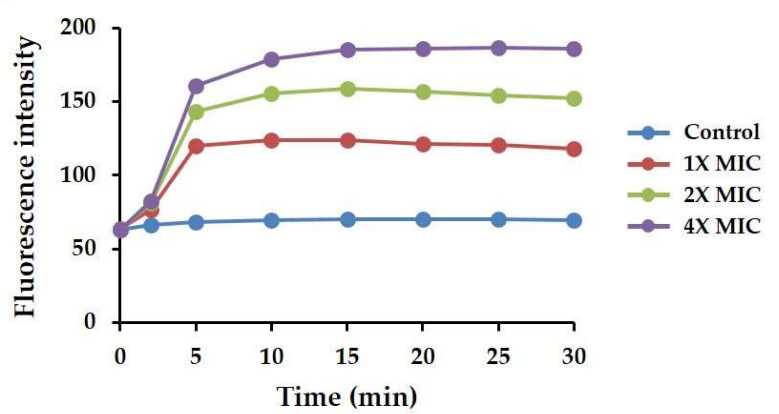

D

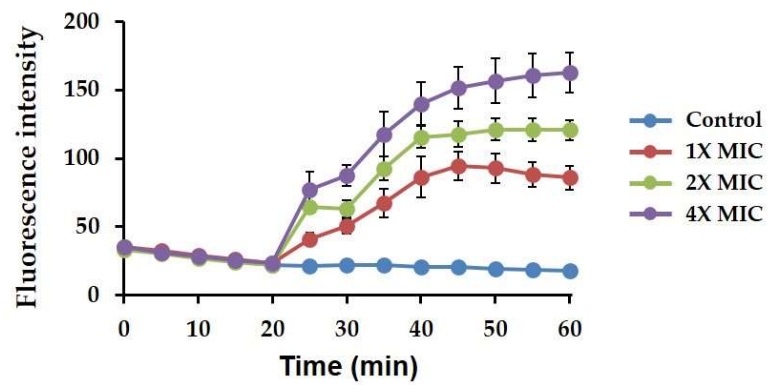

Figure 7. Magainin 2 mechanism of action. (A,B) The outer membrane permeability of magainin 2 was measured using NPN dye. (C,D) Depolarization of cytoplasmic membrane induced by magainin 2, determined using the membrane potential-sensitive fluorescent dye $\mathrm{DisC}_{3}-5$.

(A,C: Acinetobacter baumannii KCTC 2508, B,D: Acinetobacter baumannii 907233).

The ability to depolarize the A. baumannii 907233 inner membrane in the presence of magainin 2 was further confirmed using isC $_{3}-5$. DiSC ${ }_{3}-5$ is a dye that accumulates in the cytoplasmic membrane of bacteria; the dye is released when the bacteria membrane is affected by the peptide. As shown in Figure $7 \mathrm{C}, \mathrm{D}$, addition of magainin 2 resulted in increased fluorescence in a dose-dependent manner, indicating the ability of magainin 2 to depolarize the membrane. The fluorescence intensity of A. baumannii KCTC 2508 was higher than that of A. baumannii 907233 strain and decreased at $60 \mathrm{~min}$ after peptide treatment. These results suggest that magainin 2 affects the inner membranes of both A. baumannii KCTC 2508 and 907233.

\section{Discussion}

Bacterial infections are among the major causes of death worldwide [28]. Conventional antibiotics were effectively used to treat pathogenic infections for half a century, but the emergence of antibiotic-resistant bacteria has made these infections difficult to treat $[29,30]$. Generally, long-term 
exposure to antibiotics leads to resistance. Antibiotics function against proteins that are essential to bacteria cells, and mutations in bacterial proteins cause antibiotic resistance. Bacteria can also transform antibiotics and make them inefficient by producing specific enzymes. Thus, an antibacterial with a new mechanism of action differing from existing antibiotics is urgently needed. Antimicrobial peptides have distinctive mechanisms and are emerging as new therapeutic agents.

AMPs are classified according to their $\alpha$-helical, $\beta$-sheet, and random coil structures; the $\alpha$-helical structure is the most common [31]. The predicted magainin 2 structure was confirmed by CD spectroscopy to be a-helical in the bacteria membrane, mimicking the surrounding environment, and appeared as a random coil structure in an aqueous environment. In increasing concentrations of SDS and TFE, the percent of a-helix content of magainin 2 also increased. This suggests that the $\alpha$-helical structure enabled magainin 2 to interact with the bacterial membrane, which is related to its mechanism of action [32].

Because bacteria isolated from hospital patients are resistant to antibiotics, treatment of A. baumannii infection is becoming increasingly difficult [33]. Therefore, the activity of magainin 2 towards bacteria isolated from patients was evaluated. Magainin 2 exhibited lower antibacterial activity against drug-resistant $A$. baumannii than that observed against the susceptible $A$. baumannii (KCTC 2508) and exhibited more potent activity than antibiotics (ciprofloxacin and gentamicin). Thus, magainin 2 is a more effective therapeutic agent than antibiotics, which are not resistant to AMPs. Additionally, magainin 2 is not toxic to mammalian cells.

Biofilms are important for the survival of bacteria in the environment, and biofilm formation has been correlated with drug-resistance and several virulence factors [34,35]. The antibiotic resistance of biofilms is significantly higher than that of planktonic bacteria [36,37]. These biofilm-related infections are more difficult to control and can lead to death. Acinetobacter baumannii is a pathogen that commonly forms biofilm [38,39]. We analyzed the biofilm formation of $A$. baumannii strains treated with a peptide. Peptides and antibiotics showed similar abilities to inhibit biofilm formation by susceptible A. baumannii. However, in the five resistant strains, magainin 2 showed higher antibiofilm activity than antibiotics at low concentrations. These results suggest that magainin 2 exerts strong antibiofilm activity against drug-resistant $A$. baumannii. Furthermore, we evaluated the efficacy of magainin 2 on A. baumannii within established biofilms. Removing biofilms formed by pathogenic microorganisms is difficult. We found that magainin 2 was more effective than antibiotics towards removing formed biofilms. Thus, magainin 2 may be effective for treating biofilm-related infectious diseases.

The antimicrobial activity of most AMPs is strongly inhibited by presence of high ionic concentrations, which is a disadvantage as therapeutic agents in the serum or other body fluids [40]. For example, the activity of human $\beta$-defensins is influenced by $\mathrm{NaCl}$ in the airway surface liquid of cystic fibrosis patients [41]. In the presence of $\mathrm{NaCl}, \mathrm{MgCl}_{2}$, and $\mathrm{FeCl}_{3}$ at concentrations similar to those in human bodily fluids, the activity of magainin 2 was maintained. These results demonstrate that magainin 2 is stable in high-salt environments, which did not affect the killing mechanism. Combined with previous toxicity data, this peptide may be useful for therapeutic applications in a physiological environment.

AMPs, which have cationic peptides, bind to the negatively charged bacterial membrane through electrostatic interactions [42]. Peptides can disrupt the membrane after binding or enter the membrane to form pores. Pore-forming mechanisms include models of "barrel-stave", "carpet", and "toroidal-pore" [42,43]. In a previous study, magainin 2 was shown to bind to the anionic lipid bilayers of the bacterial membrane via electrostatic attractions and form a pore, which eventually destroyed the membrane [44]. The peptide was suggested to form toroidal pores $\sim 80 \AA$ diameter in DMPC/DMPG liposomes [45]. Thus, we investigated the mechanism of magainin 2 against A. baumannii strains in this study.

To determine the mechanism of action against $A$. baumannii strains, we used NPN and DiSC $_{3}-5$ dyes. First, damage to the bacterial outer membrane was monitored by measuring the fluorescence intensity of NPN. Magainin 2 induced an increase in fluorescence in both stains. Compared to the 
drug-resistant strain, the response of susceptible A. baumannii was faster. Depolarization of the bacterial cytoplasmic membrane was monitored by measuring the fluorescence intensity of $\mathrm{DiSC}_{3}-5$. Consistent with the results of the NPN test, the fluorescence intensity decreased at $55 \mathrm{~min}$, indicating that magainin 2 rapidly affected the susceptible A. baumannii. Collectively, magainin 2 has an $\alpha$-helical structure, which can associate with the $A$. baumannii membrane and uses a mechanism in which both the outer and inner membranes are affected.

\section{Materials and Methods}

\subsection{Materials}

SDS, trifluoroethanol (TFE), 3-(4,5-dimethylthiazol-2-yl)-2,5-diphenyltetrazolium bromide (MTT), dimethyl sulfoxide (DMSO), N-phenyl-1-naphthylamine (NPN), 3,3'-dipropylthiadicarbocyanine iodide ( DiSC $\left._{3}-5\right)$, ciprofloxacin, and gentamicin were purchased from Sigma-Aldrich (St. Louis, $\mathrm{MO}$, USA). Dulbecco's Modified Eagle's medium (DMEM), fetal bovine serum (FBS), and Dulbecco's Phosphate Buffered Saline (DPBS) were obtained from Welgene (Daegu, Korea).

\subsection{Microorganisms and Mouse Red Blood Cells}

Acinetobacter baumannii KCTC 2508 was obtained from the KCTC. Other Acinetobacter baumannii 244752, 409081, 719705, 892199, and 907233 were antibiotic-resistant bacteria isolated from patients at Eulji University Hospital (Seoul, Korea). The study protocol was reviewed and approved by the institutional review board of Eulji Hospital (No. EMCS 2016). All patients gave their informed consent to participate in this study or the informed consent process was waived in accordance with the decision of the ethics committee of each hospital. The mouse used in this study was carried out in strict accordance with the recommendations in the Guide for the Care and Use of Laboratory Animals of the National Institutes of Health, and approved by the Committee on the Ethics of Animal Experiments (CIACUC2017-S0042; Chosun University, Gwangju, South Korea).

\subsection{Peptide Synthesis and Sequence Analysis}

The peptides were synthesized using the solid-phase-9-fluorenylmethoxycarbonyl method as reported previously [46] on a Rink amide 4-methylbenzhydrylamine resin using a Liberty microwave peptide synthesizer (CEM, Matthews, NY, USA). The purity and molecular weight of the peptide was confirmed by reversed-phase high-performance liquid chromatography and matrix-assisted laser desorption ionization-time of flight mass spectrometry. Projections of the predicted three-dimensional structures were constructed online using the Mobyle@RPBS bioinformatics portal (http:/ / mobyle.rpbs. univ-paris-diderot.fr/cgi-bin/portal.py\#welcome), whereas the HeliQuest site (http:/ /heliquest.ipmc. cnrs.fr) was used to create helical wheel diagrams and determine the relative hydrophobic moments of the peptides.

\subsection{Circular Dichroism Measurements}

CD measurements were performed on a JASCO 810 spectropolarimeter (Jasco, Tokyo, Japan) using a $0.1-\mathrm{cm}$ path length rectangular quartz cell [47]. The peptide structure was evaluated in various solutions. The solutions were prepared at a $40 \mu \mathrm{M}$ peptide concentration in $10 \mathrm{mM}$ sodium phosphate buffer, $\mathrm{pH} 7.2$, to mimic an aqueous environment, TFE $(20 \%, 30 \%, 40 \%$, and $50 \%$ TFE) to mimic the hydrophobic environment of the microbial membrane, and SDS (5, 10, 20, and $30 \mathrm{mM} \mathrm{SDS})$ as a negatively charged prokaryotic membrane-comparable environment. The spectra were recorded between 190 and $250 \mathrm{~nm}$. The percent of $\alpha$-helix content was calculated as follows:

$$
\% \alpha \text {-helix }=-100\left([\theta]_{222}+3000\right) / 33,000
$$




\subsection{Antimicrobial Activity Assay}

The MIC of peptides was determined by the standard micro-dilution method [48] in 96-well microtiter plates. Briefly, A. baumannii strains were cultured in MHB media and prepared at $2 \times 10^{5}$ colony-forming units per milliliter $(\mathrm{CFU} / \mathrm{mL})$. The peptides were serially diluted to concentrations between 1 and $32 \mu \mathrm{M}$ in $10 \mathrm{mM}$ sodium phosphate buffer in a 96-well plate. The bacteria were mixed with serially diluted peptide in the 96 -well plate and incubated at $37^{\circ} \mathrm{C}$ for $18-24 \mathrm{~h}$. The absorbance of the sample at $600 \mathrm{~nm}$ was measured using a microplate reader and repeated three times.

\subsection{Hemolysis Assay}

The hemolytic activity of peptides was evaluated using mouse red blood cells (RBCs). RBCs were washed three times with PBS (Phosphate Buffered Saline) until the supernatant was clear. The peptides were diluted to $64 \mu \mathrm{M}$ and added to a 96-well plate. RBCs were added at a final concentration of $8 \%(v / v)$. After incubation for $1 \mathrm{~h}$, the plate was centrifuged for $10 \mathrm{~min}$ and the absorbance of the supernatant was measured at $414 \mathrm{~nm}$. The percentage of hemolysis was calculated using the following formula:

$$
\text { Hemolysis }(\%)=\left(\mathrm{A}_{414} \text { of peptide }-\mathrm{A}_{414} \text { of PBS }\right) /\left(\mathrm{A}_{414} \text { of Triton }-\mathrm{A}_{414} \text { of PBS }\right) \times 100
$$

RBCs suspended in PBS and 1\% Triton X-100 represented zero hemolysis and 100\% hemolysis, respectively.

\subsection{Cytotoxicity Assay}

The MTT assay was conducted to measure the cytotoxicity of the peptides towards HaCaT cells. $\mathrm{HaCaT}$ cells were cultured in DMEM supplemented with $1 \%$ penicillin and $10 \% \mathrm{FBS}$ at $37^{\circ} \mathrm{C}$ with $\mathrm{CO}_{2}$. Briefly, a total of $2 \times 10^{4}$ cells/well were seeded into a 96-well plate, which was incubated overnight. Peptides serially diluted with DMEM at 0-64 $\mu \mathrm{M}$ were added to each well and reacted for $23 \mathrm{~h}$. Next, $10 \mu \mathrm{L}$ of $5 \mathrm{mg} / \mathrm{mL}$ MTT was added to each well, followed by incubation for $1 \mathrm{~h}$. The supernatants were removed and dissolved by adding DMSO. Absorbance was measured at $570 \mathrm{~nm}$ [49]. The control was DMEM media without peptide. Cytotoxicity was calculated using the following formula:

$$
\text { Cytotoxicity }(\%)=100-\left[\left(\mathrm{A}_{570} \text { of peptide treated cells } / \mathrm{A}_{570} \text { of control }\right) \times 100\right]
$$

\subsection{Biofilm Inhibition Assay}

To investigate the inhibitory effect of peptide on biofilm formation, A. baumannii strains were cultured in MHB [50]. Bacteria were diluted to $5 \times 10^{5} \mathrm{CFU} / \mathrm{mL}$ in MHB supplemented with $0.2 \%$ glucose, and then $90 \mu \mathrm{L}$ of the bacterial suspension was mixed with $10 \mu \mathrm{L}$ of the peptide in a 96-well plate for $24 \mathrm{~h}$. The supernatant was then carefully removed, and the formed biofilm was fixed with $100 \%$ methanol for $10 \mathrm{~min}$. After removing the methanol, the biofilms were stained with $0.1 \%$ crystal violet for $30 \mathrm{~min}$. The plates were then washed with distilled water three times. Finally, the biofilms were completely dissolved in $95 \%$ ethanol and absorbance was measured at $595 \mathrm{~nm}$ using a Versa-Max microplate ELISA reader (Molecular Devices, Sunnyvale, CA, USA).

\subsection{Biofilm Eradication Assay}

To measure the removal effect of the formed biofilms, $100 \mu \mathrm{L}$ aliquots of $A$. baumannii 907233 $\left(5 \times 10^{5} \mathrm{CFU} / \mathrm{mL}\right)$ were incubated in MHB with $0.2 \%$ glucose and incubated for $24 \mathrm{~h}$. The culture medium was removed, and the wells were carefully washed with PBS to remove planktonic bacteria. Peptide or antibiotics were added at up to $256 \mu \mathrm{M}$ in MHB supplemented with $0.2 \%$ glucose for $24 \mathrm{~h}$. The biofilms were stained with crystal violet for $30 \mathrm{~min}$, washed three times with PBS, and dissolved in $95 \%$ ethanol. 


\subsection{Visualization of Biofilms}

To visualize the inhibition and elimination effect of the peptide on the biofilm, SYTO9 dye was used [51]. The formed A. baumannii 907233 biofilm was fixed with $100 \%$ methanol and stained with SYTO9 dye for $30 \mathrm{~min}$ in the dark. Images were obtained using an EVOS FL Auto 2 fluorescence microscope (Invitrogen, Carlsbad, CA, USA).

\subsection{Salts Sensitivity Assay}

Acinetobacter baumannii KCTC 2508 and A. baumannii 907233 strains were diluted to $2 \times 10^{5} \mathrm{CFU} / \mathrm{mL}$ in MHB media. The peptide was serially diluted from 0 to $32 \mu \mathrm{M}$ in the presence of physiological salts. The final concentrations of physiological salts were as follows: 50, 100, $150 \mathrm{mM}$ $\mathrm{NaCl}, 0.5,1,2 \mathrm{mM} \mathrm{MgCl}_{2}$, and 2, 4, $8 \mu \mathrm{M} \mathrm{FeCl}_{3}$. After these treatments, the procedures were same as used for the MIC assay described above.

\subsection{Mechanism of Action Analysis}

Outer membrane permeabilization assay. Permeation of the bacterial outer membrane by the peptide was measured by conducting a 1-N-phenylnaphthylamine (NPN) uptake assay [52]. Acinetobacter baumannii KCTC 2508 and A. baumannii 907233 strains were cultured in MHB, washed, and suspended to 0.25 at OD $600 \mathrm{~nm}$ in $5 \mathrm{mM}$ HEPES buffer. Each strain was mixed with NPN to a final concentration of $10 \mu \mathrm{M}$. Next, $50 \mu \mathrm{L}$ of peptide $(1 \times, 2 \times$, or $4 \times \mathrm{MIC})$ was added to the mixture in a 96-well plate. The relative fluorescence intensity was measured over time using a Spectramax M3 spectrophotometer (Molecular Devices) at $420 \mathrm{~nm}$.

Cytoplasmic membrane depolarization assay. The membrane potential-sensitive dye $\mathrm{DiSC}_{3}-5$ was used to measure cytoplasmic membrane depolarization [53]. Acinetobacter baumannii KCTC 2508 and A. baumannii 907233 strains were cultured in MHB and washed three times with 5 mM HEPES (pH 7.3) containing $20 \mathrm{mM}$ glucose. The bacteria were resuspended to 0.05 at OD 600 in buffer $(5 \mathrm{mM}$ HEPES, $20 \mathrm{mM}$ glucose, and $100 \mathrm{mM} \mathrm{KCl}$ ) and incubated with $1 \mu \mathrm{M} \mathrm{DiSC}{ }_{3}-5$. The fluorescence was stabilized for $1 \mathrm{~h}$ and the peptides were added to the mixture. The fluorescence was measured using a Spectramax M3 spectrophotometer with excitation at $622 \mathrm{~nm}$ and emission at $670 \mathrm{~nm}$.

\section{Conclusions}

In this study, we confirmed that magainin 2 has an $\alpha$-helix structure and showed strong antibacterial activity against $A$. baumannii including multidrug-resistant strains. Magainin 2 is not toxic towards mammalian cells and maintained its stability and excellent antibacterial activity in a biologically relevant salt environment. Magainin 2 is also effective for treating infections by inhibiting or eliminating biofilm formation. The mechanism of action of standard and drug-resistant strains is that magainin 2 acts on both the outer and inner membranes. Taken together, magainin 2 may be useful as a new antibacterial and antibiofilm agent.

Author Contributions: Data curation, S.J.K., D.W.S., S.H.K., S.A.L., J.I.L., S.H.L., E.G.H. and S.H.J.; Formal analysis, N.H.K., J.P. and E.P.; Supervision, Y.P.; Writing—original draft, M.K.K.

Funding: This work was supported by a National Research Foundation of Korea (NRF) grant funded by the Korean Government (No. 2016R1A2A1A05005440, NRF-2017M3A9E4077206), Global Research Laboratory (GRL) Grant (No. NRF-2014K1A1A2064460), and Institute for Information \& communications Technology Promotion (IITP) grant funded by the Korea government (MSIT) (No. 2017-0-01714, Development of Antimicrobial Peptide using Deep Learning).

Conflicts of Interest: The authors declare no conflict of interest. 


\section{References}

1. Laxminarayan, R.; Duse, A.; Wattal, C.; Zaidi, A.K.; Wertheim, H.F.; Sumpradit, N.; Vlieghe, E.; Hara, G.L.; Gould, I.M.; Goossens, H.; et al. Antibiotic Resistance-the Need for Global Solutions. Lancet Infect. Dis. 2013, 13, 1057-1098. [CrossRef]

2. Rice, L.B. Federal Funding for the Study of Antimicrobial Resistance in Nosocomial Pathogens: No Eskape. J. Infect. Dis. 2008, 197, 1079-1081. [CrossRef] [PubMed]

3. Boucher, H.W.; Talbot, G.H.; Bradley, J.S.; Edwards, J.E.; Gilbert, D.; Rice, L.B.; Scheld, M.; Spellberg, B.; Bartlett, J. Bad Bugs, No Drugs: No Eskape! An Update from the Infectious Diseases Society of America. Clin. Infect. Dis. 2009, 48, 1-12. [CrossRef] [PubMed]

4. Rice, L.B. Progress and Challenges in Implementing the Research on Eskape Pathogens. Infect. Control Hosp. Epidemiol. 2010, 31 (Suppl. 1), S7-S10. [CrossRef] [PubMed]

5. Santajit, S.; Indrawattana, N. Mechanisms of Antimicrobial Resistance in Eskape Pathogens. Biomed. Res. Int. 2016, 2016, 2475067. [CrossRef] [PubMed]

6. Kwon, J.; Mistry, T.; Ren, J.; Johnson, M.E.; Mehboob, S. A Novel Series of Enoyl Reductase Inhibitors Targeting the Eskape Pathogens, Staphylococcus Aureus and Acinetobacter Baumannii. Bioorg. Med. Chem. 2018, 26, 65-76. [CrossRef] [PubMed]

7. Jimenez-Guerra, G.; Heras-Canas, V.; Gutierrez-Soto, M.; Aznarte-Padial, M.d.; Exposito-Ruiz, M.; Navarro-Mari, J.M.; Gutierrez-Fernandez, J. Urinary Tract Infection by Acinetobacter Baumannii and Pseudomonas Aeruginosa: Evolution of Antimicrobial Resistance and Therapeutic Alternatives. J. Med. Microbiol. 2018. [CrossRef] [PubMed]

8. Kim, B.N.; Peleg, A.Y.; Lodise, T.P.; Lipman, J.; Li, J.; Nation, R.; Paterson, D.L. Management of Meningitis Due to Antibiotic-Resistant Acinetobacter Species. Lancet Infect. Dis. 2009, 9, 245-255. [CrossRef]

9. Guerrero, D.M.; Perez, F.; Conger, N.G.; Solomkin, J.S.; Adams, M.D.; Rather, P.N.; Bonomo, R.A. Acinetobacter Baumannii-Associated Skin and Soft Tissue Infections: Recognizing a Broadening Spectrum of Disease. Surg. Infect. 2010, 11, 49-57. [CrossRef] [PubMed]

10. Cisneros, J.M.; Rodriguez-Bano, J. Nosocomial Bacteremia Due to Acinetobacter Baumannii: Epidemiology, Clinical Features and Treatment. Clin. Microbiol. Infect. 2002, 8, 687-693. [CrossRef] [PubMed]

11. Maragakis, L.L.; Perl, T.M. Acinetobacter Baumannii: Epidemiology, Antimicrobial Resistance, and Treatment Options. Clin. Infect. Dis. 2008, 46, 1254-1263. [CrossRef] [PubMed]

12. Peleg, A.Y.; Seifert, H.; Paterson, D.L. Acinetobacter Baumannii: Emergence of a Successful Pathogen. Clin Microbiol. Rev. 2008, 21, 538-582. [CrossRef] [PubMed]

13. Fair, R.J.; Tor, Y. Antibiotics and Bacterial Resistance in the 21st Century. Perspect. Med. Chem. 2014, 6, $25-64$. [CrossRef] [PubMed]

14. Hall-Stoodley, L.; Costerton, J.W.; Stoodley, P. Bacterial Biofilms: From the Natural Environment to Infectious Diseases. Nat. Rev. Microbiol. 2004, 2, 95-108. [CrossRef] [PubMed]

15. Jamal, M.; Ahmad, W.; Andleeb, S.; Jalil, F.; Imran, M.; Nawaz, M.A.; Hussain, T.; Ali, M.; Rafiq, M.; Kamil, M.A. Bacterial Biofilm and Associated Infections. J. Chin. Med. Assoc. 2018, 81, 7-11. [CrossRef] [PubMed]

16. Zhang, L.; Gallo, R.L. Antimicrobial Peptides. Curr. Biol. 2016, 26, R14-R19. [CrossRef] [PubMed]

17. Khurshid, Z.; Najeeb, S.; Mali, M.; Moin, S.F.; Raza, S.Q.; Zohaib, S.; Sefat, F.; Zafar, M.S. Histatin peptides: Pharmacological functions and their applications in dentistry. Saudi Pharm. J. 2017, 25, 25-31. [CrossRef] [PubMed]

18. Khurshid, Z.; Naseem, M.; Sheikh, Z.; Najeeb, S.; Shahab, S.; Zafar, M.S. Oral antimicrobial peptides: Types and role in the oral cavity. Saudi Pharm. J. 2016, 24, 515-524. [CrossRef] [PubMed]

19. Khurshid, Z.; Naseem, M.; Yahya I Asiri, F.; Mali, M.; Sannam Khan, R.; Sahibzada, H.A.; Zafar, M.S.; Faraz Moin, S.; Khan, E. Significance and Diagnostic Role of Antimicrobial Cathelicidins (LL-37) Peptides in Oral Health. Biomolecules 2017, 7, 80. [CrossRef] [PubMed]

20. Khurshid, Z.; Zafar, M.S.; Naseem, M.; Khan, R.S.; Najeeb, S. Human Oral Defensins Antimicrobial Peptides: A Future Promising Antimicrobial Drug. Curr. Pharm. Des. 2018, 24, 1130-1137. [CrossRef] [PubMed]

21. Jiang, Z.; Vasil, A.I.; Hale, J.D.; Hancock, R.E.W.; Vasil, M.L.; Hodges, R.S. Effects of Net Charge and the Number of Positively Charged Residues on the Biological Activity of Amphipathic A-Helical Cationic Antimicrobial Peptides. Biopolymers 2008, 90, 369-383. [CrossRef] [PubMed] 
22. Ladram, A.; Nicolas, P. Antimicrobial Peptides from Frog Skin: Biodiversity and Therapeutic Promises. Front. Biosci. 2016, 21, 1341-1371. [CrossRef]

23. Simmaco, M.; Mignogna, G.; Barra, D.; Bossa, F. Novel Antimicrobial Peptides from Skin Secretion of the European Frog Rana Esculenta. FEBS Lett. 1993, 324, 159-161. [CrossRef]

24. Simmaco, M.; Mignogna, G.; Canofeni, S.; Miele, R.; Mangoni, M.L.; Barra, D. Temporins, Antimicrobial Peptides from the European Red Frog Rana Temporaria. Eur. J. Biochem. 1996, 242, 788-792. [CrossRef] [PubMed]

25. Zasloff, M. Magainins, a Class of Antimicrobial Peptides from Xenopus Skin: Isolation, Characterization of Two Active Forms, and Partial Cdna Sequence of a Precursor. Proc. Natl. Acad. Sci. USA 1987, 84, 5449-5453. [CrossRef] [PubMed]

26. Baker, M.A.; Maloy, W.L.; Zasloff, M.; Jacob, L.S. Anticancer Efficacy of Magainin2 and Analogue Peptides. Cancer Res. 1993, 53, 3052-3057. [PubMed]

27. Hoskin, D.W.; Ramamoorthy, A. Studies on Anticancer Activities of Antimicrobial Peptides. Biochim. Biophys. Acta 2008, 1778, 357-375. [CrossRef] [PubMed]

28. Fauci, A.S. Infectious Diseases: Considerations for the 21st Century. Clin. Infect. Dis. 2001, 32, 675-685. [CrossRef] [PubMed]

29. Fernebro, J. Fighting Bacterial Infections-Future Treatment Options. Drug Resist. Updates 2011, 14, 125-139. [CrossRef] [PubMed]

30. Thabit, A.K.; Crandon, J.L.; Nicolau, D.P. Antimicrobial Resistance: Impact on Clinical and Economic Outcomes and the Need for New Antimicrobials. Expert Opin. Pharmacother. 2015, 16, 159-177. [CrossRef] [PubMed]

31. Nguyen, L.T.; Haney, E.F.; Vogel, H.J. The Expanding Scope of Antimicrobial Peptide Structures and Their Modes of Action. Trends Biotechnol. 2011, 29, 464-472. [CrossRef] [PubMed]

32. Roccatano, D.; Colombo, G.; Fioroni, M.; Mark, A.E. Mechanism by Which 2,2,2-Trifluoroethanol/Water Mixtures Stabilize Secondary-Structure Formation in Peptides: A Molecular Dynamics Study. Proc. Natl. Acad. Sci. USA 2002, 99, 12179-12184. [CrossRef] [PubMed]

33. Del Mar Tomas, M.; Cartelle, M.; Pertega, S.; Beceiro, A.; Llinares, P.; Canle, D.; Molina, F.; Villanueva, R.; Cisneros, J.M.; Bou, G. Hospital Outbreak Caused by a Carbapenem-Resistant Strain of Acinetobacter Baumannii: Patient Prognosis and Risk-Factors for Colonisation and Infection. Clin. Microbiol. Infect. 2005, 11, 540-546. [CrossRef] [PubMed]

34. Qi, L.; Li, H.; Zhang, C.; Liang, B.; Li, J.; Wang, L.; Du, X.; Liu, X.; Qiu, S.; Song, H. Relationship between Antibiotic Resistance, Biofilm Formation, and Biofilm-Specific Resistance in Acinetobacter Baumannii. Front. Microbiol. 2016, 7, 483. [CrossRef] [PubMed]

35. Rao, R.S.; Karthika, R.U.; Singh, S.P.; Shashikala, P.; Kanungo, R.; Jayachandran, S.; Prashanth, K. Correlation between Biofilm Production and Multiple Drug Resistance in Imipenem Resistant Clinical Isolates of Acinetobacter Baumannii. Indian J. Med. Microbiol. 2008, 26, 333-337. [PubMed]

36. Babapour, E.; Haddadi, A.; Mirnejad, R.; Angaji, S.; Amirmozafari, N. Biofilm Formation in Clinical Isolates of Nosocomial Acinetobacter Baumannii and Its Relationship with Multidrug Resistance. Asian Pac. J. Trop. Biomed. 2016, 6, 528-533. [CrossRef]

37. Wang, L.; Wang, L. Acinetobacter Baumannii Biofilm Resistance Mechanisms and Prevention and Control of Progress. Discuss. Clin. Cases 2016, 3, 22-26. [CrossRef]

38. Gaddy, J.A.; Actis, L.A. Regulation of Acinetobacter Baumannii Biofilm Formation. Future Microbiol. 2009, 4, 273-278. [CrossRef] [PubMed]

39. Longo, F.; Vuotto, C.; Donelli, G. Biofilm Formation in Acinetobacter Baumannii. New Microbiol. 2014, 37, 119-127. [PubMed]

40. Huang, J.; Hao, D.; Chen, Y.; Xu, Y.; Tan, J.; Huang, Y.; Li, F.; Chen, Y. Inhibitory Effects and Mechanisms of Physiological Conditions on the Activity of Enantiomeric Forms of an Alpha-Helical Antibacterial Peptide against Bacteria. Peptides 2011, 32, 1488-1495. [CrossRef] [PubMed]

41. Goldman, M.J.; Anderson, G.M.; Stolzenberg, E.D.; Kari, U.P.; Zasloff, M.; Wilson, J.M. Human Beta-Defensin-1 Is a Salt-Sensitive Antibiotic in Lung That Is Inactivated in Cystic Fibrosis. Cell 1997, 88, 553-560. [CrossRef]

42. Jean-François, F.; Elezgaray, J.; Berson, P.; Vacher, P.; Dufourc, E.J. Pore Formation Induced by an Antimicrobial Peptide: Electrostatic Effects. Biophys. J. 2008, 95, 5748-5756. [CrossRef] [PubMed] 
43. Brogden, K.A. Antimicrobial Peptides: Pore Formers or Metabolic Inhibitors in Bacteria? Nat. Rev. Microbiol. 2005, 3, 238-250. [CrossRef] [PubMed]

44. Tamba, Y.; Yamazaki, M. Magainin 2-Induced Pore Formation in the Lipid Membranes Depends on Its Concentration in the Membrane Interface. J. Phys. Chem. B 2009, 113, 4846-4852. [CrossRef] [PubMed]

45. Han, M.; Mei, Y.; Khant, H.; Ludtke, S.J. Characterization of Antibiotic Peptide Pores Using Cryo-Em and Comparison to Neutron Scattering. Biophys. J. 2009, 97, 164-172. [CrossRef] [PubMed]

46. Fields, G.B.; Noble, R.L. Solid Phase Peptide Synthesis Utilizing 9-Fluorenylmethoxycarbonyl Amino Acids. Int. J. Pept. Protein Res. 1990, 35, 161-214. [CrossRef] [PubMed]

47. Lee, J.K.; Park, S.C.; Hahm, K.S.; Park, Y. A Helix-Pxxp-Helix Peptide with Antibacterial Activity without Cytotoxicity against Mdrpa-Infected Mice. Biomaterials 2014, 35, 1025-1039. [CrossRef] [PubMed]

48. Lee, D.G.; Kim, H.N.; Park, Y.; Kim, H.K.; Choi, B.H.; Choi, C.; Hahm, K. Design of Novel Analogue Peptides with Potent Antibiotic Activity Based on the Antimicrobial Peptide, Hp (2-20), Derived from N-Terminus of Helicobacter Pylori Ribosomal Protein L1. Biochim. Biophys. Acta 2002, 1598, 185-194. [CrossRef]

49. Cho, E.; Lee, J.; Park, E.; Seo, C.H.; Luchian, T.; Park, Y. Antitumor Activity of Hpa3p through Ripk3-Dependent Regulated Necrotic Cell Death in Colon Cancer. Oncotarget 2018, 9, 7902-7917. [CrossRef] [PubMed]

50. Kim, M.K.; Kang, H.K.; Ko, S.J.; Hong, M.J.; Bang, J.K.; Seo, C.H.; Park, Y. Mechanisms Driving the Antibacterial and Antibiofilm Properties of Hp1404 and Its Analogue Peptides against Multidrug-Resistant Pseudomonas Aeruginosa. Sci. Rep. 2018, 8, 1763. [CrossRef] [PubMed]

51. Rasamiravaka, T.; Vandeputte, O.M.; Pottier, L.; Huet, J.; Rabemanantsoa, C.; Kiendrebeogo, M.; Andriantsimahavandy, A.; Rasamindrakotroka, A.; Stevigny, C.; Duez, P.; el Jaziri, M. Pseudomonas Aeruginosa Biofilm Formation and Persistence, along with the Production of Quorum Sensing-Dependent Virulence Factors, Are Disrupted by a Triterpenoid Coumarate Ester Isolated from Dalbergia Trichocarpa, a Tropical Legume. PLoS ONE 2015, 10, e0132791. [CrossRef] [PubMed]

52. Yan, J.; Wang, K.; Dang, W.; Chen, R.; Xie, J.; Zhang, B.; Song, J.; Wang, R. Two Hits Are Better Than One: Membrane-Active and DNA Binding-Related Double-Action Mechanism of Nk-18, a Novel Antimicrobial Peptide Derived from Mammalian Nk-Lysin. Antimicrob. Agents Chemother. 2013, 57, 220-228. [CrossRef] [PubMed]

53. Nagant, C.; Pitts, B.; Nazmi, K.; Vandenbranden, M.; Bolscher, J.G.; Stewart, P.S.; Dehaye, J.P. Identification of Peptides Derived from the Human Antimicrobial Peptide Ll-37 Active against Biofilms Formed by Pseudomonas Aeruginosa Using a Library of Truncated Fragments. Antimicrob. Agents Chemother. 2012, 56, 5698-5708. [CrossRef] [PubMed] 